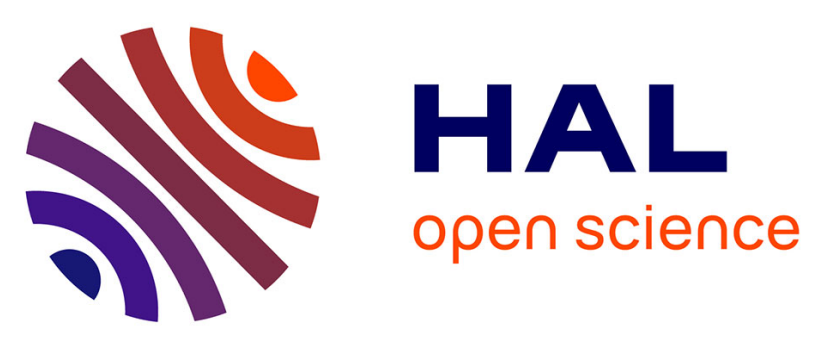

\title{
Oral sodium butyrate impacts brain metabolism and hippocampal neurogenesis, with limited effects on gut anatomy and function in pigs
}

David Val-Laillet, Sylvie Guerin, Nicolas Coquery, Isabelle Nogret, Michele Formal, Véronique Romé, Laurence Le Normand, Paul Meurice, Gwenaëlle Randuineau, Paul Guilloteau, et al.

\section{To cite this version:}

David Val-Laillet, Sylvie Guerin, Nicolas Coquery, Isabelle Nogret, Michele Formal, et al.. Oral sodium butyrate impacts brain metabolism and hippocampal neurogenesis, with limited effects on gut anatomy and function in pigs. FASEB Journal, 2018, 32 (4), pp.2160-2171. 10.1096/fj.201700547RR . hal-01771621

\section{HAL Id: hal-01771621}

\section{https://hal-univ-rennes1.archives-ouvertes.fr/hal-01771621}

Submitted on 6 Jul 2018

HAL is a multi-disciplinary open access archive for the deposit and dissemination of scientific research documents, whether they are published or not. The documents may come from teaching and research institutions in France or abroad, or from public or private research centers.
L'archive ouverte pluridisciplinaire HAL, est destinée au dépôt et à la diffusion de documents scientifiques de niveau recherche, publiés ou non, émanant des établissements d'enseignement et de recherche français ou étrangers, des laboratoires publics ou privés. 


\section{Oral sodium butyrate impacts brain metabolism and hippocampal}

2 neurogenesis, with limited effects on gut anatomy and function in

3 pigs

4 David Val-Laillet $^{1,5, *}$, Sylvie Guérin ${ }^{1}$, Nicolas Coquery ${ }^{1}$, Isabelle Nogret $^{1}$, Michèle Formal ${ }^{1}$,

5 Véronique Romé ${ }^{1}$, Laurence Le Normand ${ }^{1}$, Paul Meurice ${ }^{1}$, Gwénaëlle Randuineau ${ }^{1}$, Paul

6 Guilloteau $^{1}$, Charles-Henri Malbert ${ }^{2}$, Patricia Parnet ${ }^{3,4,5}$, Jean-Paul Lallès ${ }^{1,5}$, Jean-Pierre

7 Segain $^{3,4,5}$

$9{ }^{1}$ INRA, INSERM, Univ Rennes, UBL, Nutrition Metabolisms and Cancer, NuMeCan,

10 Rennes, France

$11{ }^{2}$ INRA, US1395 Ani-Scans, St Gilles, France

$12{ }^{3}$ INRA UMR 1280 INRA-Université de Nantes, Physiologie des Adaptations Nutritionnelles,

13 PhAN, Nantes, France.

$14{ }^{4}$ Institut des Maladies de l'Appareil Digestif(IMAD), CHU Hôtel-Dieu, Nantes, France

$15{ }^{5}$ Centre de Recherche en Nutrition Humaine Ouest (CRNHO), Nantes, France

17 Short title: Effect of oral butyrate on pig brain

19 * Corresponding author: David Val-Laillet, INRA 1341 NuMeCan, F-35590 St Gilles, $20 \quad$ France. david.val-laillet@inra.fr

22 Authors contribution: DVL, CHM, JPL, PG, PP and JPS designed the research and secured 23 funding; DVL, SG, IN, JPL and PG performed the animal experiments; DVL, SG and CHM 
24 performed brain imaging or provided analytical strategies; DVL, NC, SG and GR performed 25 brain post-mortem analyses; MF, VR, LLN, PG and JPL performed gut measurements, blood 26 and pancreas analyses; DVL, NC, PM, and JPL performed the statistical analyses; DVL wrote 27 the paper; and all co-authors read and revised the paper. 


\section{Abbreviations}

30 CA-CP: commissura anterior-commissura posterior

31 CGM: cerebral glucose metabolism

32 CTI: computed tomography imaging

33 DCX: doublecortin

34 FDG: fluorodeoxyglucose

35 GCL: granular cell layer

36 PET: positron emission tomography

37 rCGM: regional cerebral glucose metabolism

38 ROI: region of interest

39 SGZ: sub-granular zone

40 SPM: statistical parametric mapping

41 SVC: small volume correction

42

43 


\section{Abstract}

45 Butyrate can improve gut functions while HDAC inhibitors might alleviate neurocognitive alterations. Our aim was to assess whether oral butyrate could modulate brain metabolism and plasticity and if this would relate to gut function. Sixteen pigs were subjected to sodium butyrate (SB) supplementation via beverage water or water only (C). All pigs had blood sampled after 2 and 3 weeks of treatment, and were subjected to a brain positron emission tomography after 3 weeks. Animals were euthanized after 4 weeks to sample pancreas, intestine, and brain for gut physiology and anatomy measurements, as well as hippocampal histology, Ki67 and DCX immunohistochemistry. SB compared to C treatment triggered basal brain glucose metabolism changes in the nucleus accumbens and hippocampus $(P=0.003)$, increased hippocampal GCL volume $(P=0.006)$ and neurogenesis $(\mathrm{Ki67}$ : $P=0.026$; DCX: $P=0.029)$. After 2 weeks of treatment, plasma levels of glucose, insulin, lactate, GLP-1 and PYY remained unchanged. After 3 weeks, plasma levels of lactate were lower in SB compared to $\mathrm{C}$ animals $(P=0.028)$, with no difference for glucose and insulin. Butyrate intake impacted very little gut anatomy and function. These results demonstrate that oral SB impacted brain functions with little effects on the gut.

60

61 Keywords: sodium butyrate, pancreas, gut, brain metabolism, cognition, hippocampus 


\section{Introduction}

Brain and behavior alterations are observed in various pathologies including anxiety, depression, Parkinson's or Alzheimer diseases, and are also suspected to operate in dietdependent metabolic disorders and obesity $(1,2)$. Histone deacetylase (HDAC) inhibitors such as butyrate have been repeatedly shown to prevent or even treat alterations in brain functions (e.g. memory) and behavioral disorders in various rodent models of diseases like stress-induced anxiety (3) or Parkinson (4). Underlying mechanisms most often involve factors entailed in brain neurogenesis and synapse plasticity, including brain- and glial cell line-derived neurotrophic factors and nerve growth factor $(3,4)$. Interestingly, HDAC have a memory-suppressant effect that can be neutralized by HDAC inhibitors such as butyrate (5-7). In addition, long-term memory processes depend on $\mathrm{H} 3$ histone acetylation at the hippocampus level, which is favored by butyrate $(5,7,8)$. However, butyrate could also prevent memory impairment and improve cognition through the upregulation of neurotrophic factors $(3,9)$. Butyrate also functions as a ligand for a subset of $\mathrm{G}$ protein-coupled receptors and as an energy metabolite (10).

Butyrate is a short-chain fatty acid naturally produced in the gut through bacterial 81 fermentation of dietary fibers that plays an essential role in gastrointestinal tract functions. Butyrate is the primary energy source for colonocytes through mitochondrial $\beta$-oxidation and, as already mentioned, modulates gene expression through HDAC inhibition. Dietary butyrate enhanced growth rate and improved feed conversion rate before and during weaning in calves $(11,12)$ and in piglets $(13,14)$. Different studies performed in piglets or calves showed that butyrate also delayed gastric emptying $(15,16)$, increased the density of gastric parietal cells

87 (17) and colonic goblet cells (18), enhanced HSP27 and HSP70 expression in the stomach and 

colon (12), and increased the activities of many brush-border enzymes in the small intestine (12). Bioactive peptides or hormones secreted into the blood and/or locally produced in the gastrointestinal tract were suggested to be responsible for butyrate effects on gastrointestinal tract development. Altogether, these results are in favor of an effect of butyrate supplementation on the gastrointestinal tract development in mammals especially as butyrate is ingested soon after birth (19).

Whether dietary butyrate can modulate brain functions and metabolic activity in physiological situation is poorly documented. A large body of evidence suggests that butyrate can be absorbed from the gut and entirely metabolized either in the gut mucosa or in the liver, which makes it very difficult to detect butyrate in systemic blood circulation (18). But butyrate is known to cross the blood-brain barrier and to affect epigenetic machineries in the brain (20). Accordingly, monocarboxylate transporters (MCTs) that mediate the transport of monocarboxylates such as lactate, pyruvate, short-chain fatty acids and ketone bodies (21) are present in the blood-brain barrier, glial cells and neurons. Although glucose is the major fuel for normal, activated brain at the adult age (22), it is well established that ketones such as $\beta$ hydroxybutyrate and acetoacetate are alternative energy substrates during suckling, starvation or fasting periods and in situations of ketosis induced by high-fat diet (23-25). Several human and animal studies using ${ }^{18} \mathrm{~F}$-fluorodeoxyglucose (FDG) and positron emission tomography (PET) provided evidence that cerebral metabolism of glucose is reduced during ketosis (2527). However, it is not known whether butyrate, produced in the gastrointestinal tract and present at low levels $(\mu \mathrm{M})$ in blood, can modulate regional brain glucose metabolism.

The aim of the present study was to test the hypothesis that oral sodium butyrate supplementation modulates brain metabolic activity and hippocampal structural plasticity, and that part of this modulation stems in the effects of butyrate on gut biology and barrier 
112 function. We tested this hypothesis in growing pigs as we developed brain imaging in this

113 species for investigating diet-induced brain and behavior modulations $(2,28,29)$. The pig is

114 now recognized as a valuable alternative model to rodents for investigating human nutrition,

115 gastrointestinal tract development and gut-brain axis interplay (19, 30). Besides, butyrate

116 supplementation was shown to improve development of gastrointestinal tract anatomy and

117 functions in young mammals $(13,31)$. Exploring different pancreatic and intestinal 118 parameters might contribute to identify potential gut-brain communication pathways for the 119 putative effects of oral butyrate supplementation on brain biology.

\section{Materials \& Methods}

The present experiment was conducted in accordance with the current ethical standards of the European Community (Directive 2010/63/EU), agreement No. A35-622 for the

124 experimental facilities, and authorization No. 35-88 to experiment on live animals for the 125 principal investigator of the study. The Regional Ethics Committee in Animal Experiment of Brittany (France) validated the entire procedure described in this paper (R-2012-DVL-01).

\section{Animals and housing}

Four successive batches of four Large White/Landrace $\times$ Piétrain 2.5-month-old female

129 growing pigs of $28.9 \pm 1.2 \mathrm{~kg}($ mean $\pm \mathrm{SEM})$ body weight $(\mathrm{BW})$ at the beginning of the study

130 were used. The piglets were weaned at 28 days of age and subsequently housed in individual 131 pens (length $80 \times$ width $60 \times$ height $68 \mathrm{~cm}$ ) equipped with a feeding trough and a drinking

132 nipple. The room temperature was kept at $23.4 \pm 0.1^{\circ} \mathrm{C}$ with a $13: 11$-h light-dark cycle. 

weaning and then a starter diet until the end of the study (at approximately 3.5 months after

137 amino acids) met or exceeded recommendations of the NRC (1998) throughout the 138 experimental period (see 32 for the composition of the diets). Animals were divided into

139 two experimental groups. Sodium Butyrate group, SB: $28.7 \pm 0.9 \mathrm{~kg}$; Control group, C: $14029.2 \pm 0.9 \mathrm{~kg})$, with two animals per group in each batch $(\mathrm{n}=8$ animals per group in total), 141 and were weighed weekly. During the whole experiment, all the pigs received $40 \mathrm{~g}$ of feed per

$142 \mathrm{~kg} \mathrm{BW}$, which corresponds to the usual allowance in the pig facilities. Ad libitum feeding was 143 not used in this study to limit feed intake variability across individuals and to prevent feed

144 refusals. Indeed, the amount of butyrate supplied to the SB pigs was based on the amount of 145 feed ingested. The daily feed allowance was distributed once a day at $0930 \mathrm{~h}$. One hour before 146 meal provision, at $0830 \mathrm{~h}$, the animals received either water alone (control, C group) or a 10$147 \mathrm{mM}$ sodium butyrate solution (SB group). Access to tap water was permitted only once the 148 amount of water or butyrate solution was completely consumed, and was then presented again 149 in the mid-afternoon until the next day. The present dosage of butyrate $(110 \mathrm{mg} / \mathrm{kg} \mathrm{BW} /$ day $)$ 150 is within the physiological range used in other studies with pigs $(13,31)$ and rodents $(33,34)$. 151 Control animals received only tap water.

\section{Surgical implantation of jugular catheter}

Animals were fitted with a jugular catheter under general anaesthesia performed as

154 previously described (35) to achieve 2.2 Minimum Alveolar Concentration (MAC) for 155 isoflurane. Analgesia was achieved with an additional infusion of Fentanyl (30 to 100 $156 \mu \mathrm{g} / \mathrm{kg} / \mathrm{hr}$ IV, Renaudin, Paris, France) during surgery. A silicon catheter was introduced into the external jugular vein and tunnelled subcutaneously to exit in the interscapular space. 
158 Animals were allowed to recover for one week after the surgical procedure before any

159 observation or treatment was made.

\section{Blood sampling and analyses}

All the jugular blood samples were collected in tubes $(10 \mathrm{ml})$ containing ethylene diamine tetraacetate (EDTA) (VT-100 STK, $0.1 \mathrm{ml}$ EDTA, $0.47 \mathrm{ml} / \mathrm{l}: 21 \mathrm{w} / \mathrm{v} \%$, CML, Nemours, France). Moreover, a protease inhibitor cocktail (ref P2714-1BTL, SIGMA, L'isle d'Abeau Chenes, Saint-Quentin Fallavier, France) was added to tubes aimed at GLP-1 assays. Two weeks after the beginning of treatments, samples were collected just before $(0830 \mathrm{~h})$ the distribution of the experimental treatments (tap water alone for the $\mathrm{C}$ group, sodium butyrate solution for the SB group) and $1 \mathrm{~h}$ after $(0930 \mathrm{~h})$, i.e. just before feeding (for lactate, insulin, peptide YY - PYY, GLP-1 and osmolality measurements). Three weeks after the beginning of the treatments, other samples were also collected in anaesthetized animals just before brain imaging (for glucose, lactate and insulin measurements). All blood samples were kept in ice before plasma preparation by centrifugation $\left(2300 \mathrm{xg}, 10 \mathrm{~min},+4^{\circ} \mathrm{C}\right)$. Plasma was recovered, aliquoted and stored frozen at $-40^{\circ} \mathrm{C}$ until analysis.

174 Glucagon Like Peptide-1 (Active)Elisa Immuno Assay Kit (ref. EGLP-35 K, Merck KGaA,

175 Darmstadt, Germany). Peptide YY plasma concentrations ( $\mathrm{ng} / \mathrm{ml})$ were determined using a commercial PYY Elisa Immuno Assay Kit (ref. EK-059-04, Phœnix Pharmaceuticals, INC., ,

177 Burlingame, CA 0, USA). Insulin concentration was measured by RIA (Insulin-CT;

178 CisbioBioassays, Codolet, France). Plasma levels of glucose and lactate were measured in 179 duplicate by automated spectrophotometry (Konelab 20i; Thermo Fisher Scientific, Waltham, 180 MA, USA). Plasma osmolality was measured on a micro-osmometer (Hermann Roebling 181 12/12 DR, Berlin, Germany). 
After three weeks of treatment, the animals underwent a brain-imaging session to investigate basal brain metabolism. The brain imaging modality used to investigate the regional cerebral glucose metabolism (rCGM) was the positron emission tomography (PET) of ${ }^{18} \mathrm{~F}$-fluorodeoxyglucose $\left({ }^{18} \mathrm{~F}-\mathrm{FDG}\right.$, CIS bio international, France). The procedure for animal preparation and anesthesia was similar to that described in our previous publications $(36,37)$. The animals were placed in a head first supine position on the bed of a whole body, high-resolution PET. A venous catheter was then inserted into their left ear in order to inject the ${ }^{18}$ fluoro-deoxyglucose radiolabel $\left({ }^{18} \mathrm{~F}-\mathrm{FDG}, 200 \mathrm{MBq}\right.$ in $\left.20 \mathrm{ml}\right)$, at least $30 \mathrm{~min}$ after the beginning of anesthesia. Brain images were acquired on a computed tomography imaging machine in 3D mode (CTI/Siemens ECAT, 962, $\mathrm{HR}+)$ and processed as described in Clouard et al. (36).

\section{Euthanasia, organ and tissue collection}

After four weeks of treatment, the pigs were euthanized with intravenous administration of T61 ${ }^{\circledR}$ following a pre-anesthesia with ketamine $(5 \mathrm{mg} / \mathrm{kg}$ intramuscularly, Rhône Mérieux, Lyon, France), and then exsanguinated.

Brain collection, fixation and conservation. After euthanasia, the pigs were decapitated and the head was perfused via the carotids with $2 \mathrm{~L}$ of $1 \%$ sodium nitrite and $5 \mathrm{~L}$ of buffered $4 \%$ formalin at $4{ }^{\circ} \mathrm{C}$. The brains were kept in buffered $4 \%$ formalin during $24 \mathrm{~h}$ and then transferred in $30 \%$ sucrose with $0.1 \%$ sodium azide at $4^{\circ} \mathrm{C}$ until being sliced with a cryomicrotome. Brain slices were deposited on glass slides and stored at $-20^{\circ} \mathrm{C}$.

Gut tissue collection. Two pigs per afternoon (one C and one SB) were randomly slaughtered at $30 \mathrm{~min}$ intervals, $2.5 \mathrm{~h}$ after the last treatment (tap water $v s$. sodium butyrate solution, but no meal). After laparotomy, the entire gastrointestinal tract was carefully removed and the small intestine was isolated by ligation before removal. The pancreas was 
weighed and three pieces (about one g per sample) were gently collected, frozen in liquid nitrogen and then stored at $-20^{\circ} \mathrm{C}$ until enzyme activity analysis. The mesentery was removed

209 all along the small intestine that was then measured. Twenty five-centimeter segments of 210 duodenum (20 cm distal to Treitz ligament), mid-jejunum and distal ileum (ending $10 \mathrm{~cm}$

211 proximal to the ileo-cecal valvula) were cut, emptied of digesta contents and gently rinsed

212 with cold saline. For each collected segment, cross-sectional tissue samples were made for the 213 following preparations or analysis: $15 \mathrm{~cm}$ for immediate use in Ussing chambers (not

214 duodenum) and quickly transported to the laboratory in cold Ringer bicarbonate solution (see 215 below); $5 \mathrm{~cm}$ for fixation (in buffered formalin 10\%), paraffin embedding and histology; and $2161 \mathrm{~cm}$ of whole tissue (cut in small pieces) for HSP analysis was snap-frozen in liquid nitrogen 217 and then stored at $-80^{\circ} \mathrm{C}$. Part of the remaining collected tissues was scraped using a glass 218 slide (small intestine, $4-5 \mathrm{~cm}$ ) or cut into small pieces (colon, $1 \mathrm{~cm}$ ) for enzyme 219 determination, snap-frozen and then stored at $-20^{\circ} \mathrm{C}$.

\section{Brain immunohistochemical analysis}

Brain immunohisto-fluorescence was performed on $30-\mu \mathrm{m}$ brain sections of the left hippocampus. One section every 25 sections was selected for antigen Ki67 and doublecortin (DCX) immunohistochemistry. Only the first 10 selected sections were gathered and used for immunohistochemistry, which covers approximately half of the hippocampus, i.e. $7.5 \mathrm{~mm}$ over around $15 \mathrm{~mm}$ (see 38 for comparison with whole hippocampus sampling). Ki67 and DCX staining was performed on adjacent sections for each hippocampal progression site. Ki67 protein is expressed in proliferating cells while DCX is a microtubule-associated protein expressed by neuronal precursor cells and immature neurons (39).

Sections were thawed during $10 \mathrm{~min}$ at room temperature and washed three times for $23010 \mathrm{~min}$ in phosphate buffered saline (PBS). After the last wash, $150 \mu \mathrm{L}$ of blocking buffer 
231 (PBS solution, Gibco by Life Technologies; 10\% horse serum, Sigma; 0.3\% Triton, Sigma) 232 was then dropped on the region of interest (ROI) and incubated during $1 \mathrm{~h}$ at room 233 temperature in a humidity chamber. Blocking buffer excess was carefully removed with 234 absorbent tissue and $150 \mu \mathrm{L}$ of primary antibody (Ki67: Anti-Ki67 antibody ab15580, 235 dilution 1:200, Abcam; DCX: Anti-doublecortin (C-18) antibody sc8066 1:200, Santa Cruz) 236 was added on the ROI. Parafilm was carefully laid on tissue slice and slides were stored at 237 $4^{\circ} \mathrm{C}$ for at least $16 \mathrm{~h}$ until the next morning. Sections were then washed three times with blocking buffer for $10 \mathrm{~min}$ and $150 \mu \mathrm{L}$ of secondary antibody (Ki67: Alexa Fluor 488

239 Conjugate 1/200, Cell Signaling Technology; DCX: $\mathrm{Cy}^{\mathrm{TM}}$ 3-conjugated AffiniPure Donkey 240 Anti-Goat IgG (H+L) 1:500, Jackson ImmunoResearch Laboratories, West Grove, PA, USA) 241 was added for a 2-h incubation at room temperature. Slides were finally mounted with 242 Fluoroshield Mounting Medium with 4',6-diamidino-2-phenylindole (2 drops per slide, ref 243 17513, Abcam, Cambridge, UK). Sections were examined under a fluorescent microscope 244 (Eclipse 80i, Nikon), digitized and large-field mosaics were performed with micro-manager 245 (Image J plugin) in order to get the whole hippocampal section on one image.

Determination of hippocampus and granular cell layer (GCL) volumes, number of 247 Ki67-positive nuclei in the sub-granular zone (SGZ), number of DCX-positive cells in the 248 GCL were performed for each selected hippocampal section and reported as an inferred value 249 per site considering that each site is a block of 25 sections.

\section{Gut physiology measurements ex vivo (Ussing chambers)}

Electrophysiology ex vivo. Six Ussing chambers (2 per gut site; P2250 model;

252 Physiological Instruments, San Diego, CA, USA) were used for investigating gut 253 electrophysiology (and permeability, see below) in each pig. Jejunal, ileal and colonic 254 mucosae were stripped off the muscular layers, cut into two adjacent pieces and immediately 
mounted in chambers $\left(1 \mathrm{~cm}^{2}\right.$ mucosa in contact with $2.5 \mathrm{ml}$ Ringer bicarbonate buffers). Gut electrophysiology (and permeability) parameters in basal conditions were measured in the two chambers and values averaged per tissue. Then, one chamber was kept in basal condition while the other was used for measurements under oxidative stress using monochloramine 259 (final concentration $1 \mathrm{mM}$, both sides of the tissue) (40). The Ringer-bicarbonate buffer 260 contained $16 \mathrm{mmol} / \mathrm{L}$ of glucose and $16 \mathrm{mmol} / \mathrm{L}$ of mannitol on the serosal and mucosal 261 sides, respectively. Chambers were kept at $39^{\circ} \mathrm{C}$ and buffers oxygenated all the time 262 automatically. Tissue viability was checked every $30 \mathrm{~min}$ by recording tissue electrical 263 potential difference automatically. Gut mucosae were left equilibrating for 20 min before 264 short-circuit current (Isc) and the trans-epithelial electrical resistance (TEER) were 265 determined under clamp condition ( $3 \mathrm{mV}$ for $300 \mathrm{~ms}$ every $30 \mathrm{~s}$ ) using Ohm's law (41). 266 Colonic mucosa sodium-dependent glucose absorption capacity and chloride secretion 267 capacity were determined after addition of D-glucose (16 mM, mucosal side) and the 268 cholinergic agonist carbachol (1 mM, serosal side), respectively (41).

Trans- and para-cellular permeability ex vivo. Gut mucosa permeability to FITC270 dextran 4000 (FD4, MW $4 \mathrm{kDa}$; para-cellular permeability marker) and horseradish 271 peroxidase (HRP type II, MW $40 \mathrm{kDa}$; trans-cellular permeability probe) was assessed 272 exactly as previously described for the small intestine and the colon $(42,43)$. When tissue 273 electrophysiology was stabilized (see above), FD4 and HRP were added to the mucosal side 274 of tissues and serosal fluid $(200 \mu \mathrm{L}$, replaced by $200 \mu \mathrm{L}$ Ringer-glucose) was collected 275 kinetically (every $30 \mathrm{~min}$ for $120 \mathrm{~min}$ ). Fluid FD4 and HRP concentrations were determined 276 by fluorimetry and spectrophotometry, respectively and marker transmucosal flows were 277 calculated as detailed previously (44). 
280 pieces of tissues were collected at various sites along the gut (see above) and were dehydrated 281 and then embedded in paraffin as reported previously (42, 43). Five-micrometer tissue 282 sections were prepared, dewaxed, rehydrated and stained with eosin and haematoxylin, and 283 villi and crypts (10-15 per section, well oriented, full size) were measured for their length, 284 width and surface area (42, 43). Intestinal villus height-to-crypt depth (VH:CD) ratio, and ' $\mathrm{M}$ ' 285 ratio for estimating three-dimension mucosal surface area (45) were also calculated. Villous 286 and crypt morphology parameters were averaged per site per pig before statistical analysis. pancreas tissue and intestinal mucosa, protein content was measured and three pancreatic enzymes (trypsin, E.C. 2.3.21.4; lipase, E.C. 3.1.1.3; amylase, E.C. 3.2.1.1.) were analyzed as reported before (46). The activities of five enzymes - two peptidases (amino-peptidase N, E.C. 3.4.11.2; dipeptidyl-peptidase IV, DPP4, E.C. 3.4.14.5), two disaccharidases (sucrase, E.C. 3.2.1.48; maltase, E.C. 3.2.1.20) and one phosphatase (intestinal alkaline phosphatase, E.C. 3.1.3.1) - were determined in small intestinal mucosa homogenates as previously reported $(42,43)$. Alkaline phosphatase activity was also determined in a piece of tissue from proximal colon. Specific (/g protein) and total (/kg of BW for pancreas, and $/ \mathrm{g}$ fresh mucosa for intestine) enzymes activities (or activity concentrations for intestinal alkaline phosphatase) were calculated as previously reported.

Gut heat shock proteins. Inducible heat shock proteins HSP27 and HSP70 were determined in gut tissues as reported before $(42,43)$.

\section{Statistical analysis}


blood plasma data were analyzed with a simple ANOVA or an ANOVA for repeated measurements over time to compare data obtained before and after water $v s$. butyrate intake. Interactions between treatment and time were also investigated (SPSS Statistics software version 20.0; IBM, Somers, NY, USA). All data are reported as means \pm SEMs. The level of significance for all analyses was set as $P<0.05$ and trends were considered at $0.05 \leq \mathrm{P} \leq$ $308 \quad 0.10$.

Brain immunodetection data. For the immunohistochemistry data, animal numbers are $\mathrm{N}=7$ for Control group (C) and $\mathrm{N}=6$ animals for Butyrate group (SB). Two animals (1 C and 1 SB) were excluded because of an incorrect slicing axis or unsuccessful 312 immunohistochemistry, respectively. Hippocampal site-based statistical analyses were 313 performed with an ANOVA (SPSS Statistics software version 20.0; IBM, Somers, NY, USA), 314 with hippocampal site progression and animal as covariates. Data are presented as mean 315 values for the entire block of 25 slices for each hippocampal site.

Statistical brain image analysis. The regional ${ }^{18}$ F-FDG uptake was standardized to the

317 brain global uptake using proportional scaling in order to suppress individual differences in 318 global cerebral glucose metabolism (CGM). Brain images were analyzed using independent $t$ 319 tests to compare the Butyrate (SB) and Control (C) groups with the two following contrasts: $320 \mathrm{SB}>\mathrm{C}$ and $\mathrm{SB}<\mathrm{C}$. After a whole-brain first-level analysis without a priori, we performed 321 small volume correction (SVC) analyses on ROIs, upon a priori hypotheses, i.e. in areas 322 associated with learning and memory, attentional processes, reward and cognitive control 323 (anterior prefrontal cortex, dorsolateral prefrontal cortex, orbitofrontal cortex, cingulate 324 cortex, hippocampus, parahippocampal cortex, amygdala, caudate, putamen, nucleus 325 accumbens, globus pallidus). With this analysis, allowing for voxel-to-voxel comparisons 326 within restricted ROIs, we managed to identify the voxels for which the activity was 327 statistically different between groups (treatments) in the ROIs. For the SVC analyses, the 
328 value of $P=0.05$ (uncorrected for multiple comparisons) was set as the significance threshold 329 with a cluster size $k \geq 25$ voxels. The statistical analysis with Statistical Parametric Mapping 8

330 (SPM8) produced a listing of voxels for which the activation differed between treatments.

331 Each voxel was associated with a set of coordinates $\left(\begin{array}{ll}x & y \\ z\end{array}\right)$ corresponding to its spatial

332 location in the commissura anterior-commissura posterior (CA-CP) plane with $\mathrm{CP}$ set as the

333 origin. The ROIs chosen for the SVC analysis were anatomically identified on the basis of a

334 3D digitized pig brain atlas developed in our laboratory (47).

Statistical analysis of intestinal parameters. Intestinal parameter data were analyzed using the Statistical Analyzing System (version 8.1, 2000; SAS Institute Inc., Cary, NC) using models that included the treatment $(\mathrm{C} v s . \mathrm{SB})$ the site and the treatment by site interaction.

338 MIXED procedures with REPEATED statement for gut sites were used. Results are presented

339 as least-square means and pooled SEM. Least-square means comparisons for each

340 combination of treatment and site were made only when a tendency $(P \leq 0.10)$ for a treatment

341 by site interaction was observed. In these cases, means were separated using Bonferroni post-

342 hoc comparison test. Permeability data displaying non-Gaussian distribution were log343 transformed before statistical analysis. Effects were considered significant at $P<0.05$ and as 344 trends at $0.05 \leq P \leq 0.10$.

\section{Results}

\section{Body weight and blood analyses}

During the whole experiment, there was no significant difference in BW between groups (from $29.2 \pm 0.9$ to $42.0 \pm 1.0 \mathrm{~kg}$ in $\mathrm{C}$ pigs, from $28.7 \pm 0.9$ to $41.9 \pm 1.5 \mathrm{~kg}$ in $\mathrm{SB}$ 
animals, from $P=0.494$ to $\mathrm{P}=0.949$ ). All the pigs consumed their daily ration and there was no difference in feed consumption between groups.

Blood analyses before and after drinking (after two weeks of treatment). Lactate (Fig 1A), PYY (Fig 1B) and GLP-1 (Fig 1C) jugular plasma levels significantly decreased after drinking, independently from the treatment (lactate, from $922 \pm 93$ to $695 \pm 48 \mu \mathrm{mol} / \mathrm{l}$, $P=0.040 ; \mathrm{PYY}$, from $2.9 \pm 0.2$ to $2.7 \pm 0.2 \mathrm{ng} / \mathrm{ml}, P=0.0140 ; \mathrm{GLP}-1$, from $14.4 \pm 1.8$ to $13.4 \pm 1.7 \mathrm{pM}, P=0.023)$. There was an interaction between treatment and time $(P=0.025)$ for osmolality that increased in SB pigs and decreased in $\mathrm{C}$ pigs after beverage drinking (Fig 1D). There were no other effects for these four parameters. No effect of the treatment or sampling time nor interaction was observed for plasma glucose and insulin (data not shown). lower lactate jugular plasma levels than $\mathrm{C}$ pigs $(782 \pm 52$ vs. $1087 \pm 114 \mu \mathrm{mol} / \mathrm{l} ; P=0.028)$ (Fig 1E). There was no difference between groups for the glucose and insulin jugular plasma levels (data not shown).

\section{Regional brain glucose metabolism}

The without a priori analysis revealed very few structures with basal activity differing between groups (Table 1). The right hippocampus $(P=0.003)$, the right primary somatosensory cortex $(P<0.001)$ and left inferior colliculus $(P=0.002)$ were more activated

368 in the SB group than in the $\mathrm{C}$ group. The left primary somatosensory cortex $(P=0.002)$ and

369 the left inferior temporal gyrus $(P=0.004)$ were less activated in the SB group than in the $\mathrm{C}$ 370 group. 
nucleus accumbens was less activated in the SB group than in the $\mathrm{C}$ group $(P=0.010)$, while both activated $(P=0.003)$ and deactivated $(P=0.010)$ clusters were found in the right hippocampus in the SB group compared to C group.

Fig 2 indicates the activated and deactivated clusters for the image contrast analyses comparing the SB group to C group.

\section{Hippocampal structural plasticity}

Hippocampal and GCL volumes increased along the hippocampus site progression (Fig 3). Along hippocampal progression, similar hippocampal volume was measured, whereas the GCL volume was significantly higher in the SB group (Fig 3B, $P=0.006$ ). Ki67-positive nuclei and DCX-positive cells were detected in order to assess the structural plasticity of the hippocampus. Both Ki67-positive nuclei density and DCX-positive cells density appeared higher in the SB group compared to C group (Fig 4A). Along hippocampal site progression, significantly higher numbers of Ki67-positive nuclei and DCXpositive cells were noticed in the SB group as compared to $\mathrm{C}$ group (Fig 4B; Ki67: $P=0.026$; DCX: $P=0.029)$.

\section{Gut physiology ex vivo (Ussing chambers)}

Electrophysiology ex vivo. Mucosal electrophysiology parameters were determined in both basal and oxidant stress conditions (Table 2). Basal Isc did not display any significant treatment by site interaction, or treatment or site effect. Basal glucose absorption capacity (dIsc-glucose) displayed a significant treatment by site interaction $(P=0.04)$, but no treatment or site effect. The interaction and site effects were not significant for chloride secretion capacity (dIsc-carbachol) but treatment effect in basal condition tended to be significant $(\mathrm{SB}<\mathrm{C}, P=0.09)$ for this variable. 
Trans- and para-cellular permeability ex vivo. There was no significant treatment by site interaction for both permeability markers and measurement conditions (Table 3). However, HRP (trans-cellular) permeability in basal condition tended to be globally lower in SB compared to $\mathrm{C}$ treatment $(P=0.09)$. Treatment differences for FD4 (para-cellular 400 permeability) in basal or stress condition did not reach significance (Table 3).

\section{Gut anatomy, enzyme activities and heat shock proteins (HSP)}

Intestinal length and villous-crypt architecture. Small intestinal length did not differ between $\mathrm{C}$ and SB groups (respectively 0.34 and $0.35 \mathrm{~m} / \mathrm{kg} \mathrm{BW}, \mathrm{SEM}=0.042 ; P=0.620$ ). Similarly, there was no significant treatment by site interaction or significant difference between treatments for all parameters of villous-crypt (small intestine), crypt (colon) architecture, villous height-to-crypt depth ratio or $\mathrm{M}$ factor (Table S1, Supplemental Material). By contrast, and as expected, site effects were (highly) significant for all the studied variables, except villous perimeter and crypt depth (Table S1).

Pancreatic and intestinal enzyme activities. No effect of butyrate ingestion was shown concerning pancreas and intestine protein contents as well as pancreatic enzyme activity

411 levels (Table 4). There was a tendency $(P=0.063)$ for a treatment by site interaction for 412 amino-peptidase $\mathrm{N}$, showing that this enzyme total activity was lower in SB than C group in 413 the jejunum $(P<0.05)$, with no differences in the duodenum or ileum. There was a tendency $414(P=0.07)$ for a treatment by site interaction for DPP4 specific activity, though without 415 significant differences at any site. There was no significant treatment by site interaction or treatment differences for disaccharidases and intestinal alkaline phosphatase activities (Table

417 5). Site effect was highly significant $(P<0.0001)$ for all the analyzed intestinal enzymes. 
differences for these HSPs (Table S2, Supplemental Material). Site effect was (HSP27, $P<0.0001)$ or tended to be (HSP70, $P=0.07)$ significant.

\section{Discussion}

The main result of this study is that butyrate supplementation via beverage water during 3-4 weeks in growing pigs fed a standard diet can trigger regional brain glucose metabolism

427 changes in several brain structures, including the hippocampus. An increased glucose metabolism relative to overall brain metabolism was detected in the right hippocampus with the first-level analysis and then confirmed with the SVC analysis. This second-level analysis performed on specific regions of interest also detected deactivated clusters in the right hippocampus and nucleus accumbens. Increased hippocampal plasticity was also detected in

432 post-mortem histochemical analyses, with more neurogenesis and an increased GCL volume.

433 Blood analyses revealed lower plasma levels of lactate in the SB group compared to the C group at the moment of brain imaging, but no difference in terms of glucose or insulin levels. This result demonstrates that the differences in basal brain activity observed between groups were not attributable to modifications in plasma glycaemia at the time of brain imaging.

437 Incidentally, there was no short-term effect of butyrate intake on lactate, glucose, PYY, GLP4381 and insulin plasma levels either, indicating that the butyrate effect on regional brain 439 metabolism, perceivable at a distance from butyrate ingestion, was not related to systemic 440 glucose control or gut hormones variations. The absence of treatment effect for GLP-1 and 441 PYY plasma levels was quite surprising because butyrate is known to stimulate the release of 442 GLP-1 from intestinal L-cells (48) and increase fasting and postprandial plasma PYY 443 concentrations when infused in the colon (49). GLP-1 can improve learning and memory via 
444 an action at the hippocampal level (50), but this mechanism was probably not at the origin of 445 the effects observed in our study. It is also possible that butyrate never reached L-cells and 446 was absorbed at the stomach level, which would prevent any significant increase of plasma 447 GLP-1. In this case, the gut-brain communication pathway involved needs further 448 investigation.

Our results showed that chronic butyrate supplementation led to a decreased regional 450 glucose metabolism in the dorsal hippocampus and nucleus accumbens, as well as an increased regional glucose metabolism in the ventral hippocampus, together with an increased GCL volume and hippocampal neurogenesis. These data suggest that butyrate, which is largely metabolized by the gut and the liver, and thus found at very low concentrations $(\mu \mathrm{M})$ 454 (18), may influence brain glucose metabolism. It was previously shown in a rat model of spreading depression, that ${ }^{14} \mathrm{C}$-labelled butyrate, injected intravenously, was readily taken up and metabolized by adult brain, probably by astrocytes (20). Moreover, this study showed that enhanced cortical butyrate uptake parallels local increase in ${ }^{14} \mathrm{C}$-deoxyglucose utilization (20). However, the increased glucose metabolism found in some brain regions of the SB groups is 459 in contrast with its reduction generally observed under ketogenic diets $(26,27,51)$. The 460 reduction of brain glucose (oxidative) metabolism during ketosis correlates with the increase 461 in plasma ketones (acetoacetate and $\beta$-hydroxybutyrate) concentration (mM), and is 462 associated with the increase of cerebral metabolic rate of ketones $(26,27,51)$. It has been 463 proposed that the tricarboxylic acid cycle (TCA) is fed by acetyl-CoA derived from ketones 464 thereby decreasing glucose oxidation downstream pyruvate dehydrogenase (PDH) (51). 465 However, concerning butyrate, there is no evidence for such a metabolic behaviour in brain 466 cells. One explanation for the discrepancy in our observation of a stimulation of glucose 467 metabolism could be that, in comparison to the high concentration of ketones supplying the 468 brain, butyrate brain levels may be too low to compete with glucose oxidation. Alternatively, 
butyrate-stimulated brain glucose metabolism could implicate the ability of butyrate to act as an HDAC inhibitor, thereby upregulating the transcription of genes involved in glucose metabolic pathway. Indeed, a transcriptomic study of the human colonic mucosa reported that butyrate stimulated the transcription of $\mathrm{PDH}$, citrate synthase (TCA enzyme) and succinate deshydrogenase (respiratory chain) (52). Furthermore, using germ-free mice, Donohoe et al. (53) suggested that butyrate stimulates mitochondrial oxidation of glucose in colonic epithelial cells. Interestingly, Moretti et al. (9) showed that sodium butyrate treatment in a rat model of mania modified mitochondrial function in prefrontal cortex, hippocampus, amygdala and striatum. Therefore, our data could suggest that increasing colonic production of butyrate, for example with fibre-enriched diets, could influence brain glucose metabolism.

The dorsal and ventral parts of the hippocampus are two functionally different structures that are connected to different neuronal networks (54). The dorsal hippocampus performs primarily cognitive functions whereas the ventral hippocampus relates to stress, emotions and affect. For example in rats, lesions in the dorsal hippocampus caused spatial memory impairment in the radial arm maze, contrary to lesions in the ventral hippocampus

484 (55), and stress-related genes were found expressed in the ventral hippocampus of prenatally 485 stressed rats (56). Interestingly, ventral hippocampal afferents to the nucleus accumbens were also found regulating susceptibility to depression (57). If the changes of regional metabolism 487 in the nucleus accumbens and hippocampus further to butyrate supplementation were confirmed in a pig model of anxiety/depression, early malnutrition, or neurocognitive alterations, then behavioral tests might reveal whether these brain modulations are 490 accompanied by changes in cognitive abilities and susceptibility to stress or anxiety. 491 Interestingly, we previously demonstrated that perinatal administration of butyrate to dams 492 improved performance in the spatial memory test on young rats that visited more frequently 493 the novel arm during a Y-maze test (58). Gieling et al. (59) reviewed studies in pig cognition 
and identified several promising types of tasks such as versatile spatial free-choice type tasks allowing for simultaneous measurement of several behavioural domains. In a recent study, we showed that piglets with unbalanced perinatal nutrition had smaller hippocampal granular cell layer and decreased neurogenesis, as well as different cognitive responses compared to control animals during a spatial memorization and learning task (38). These pig models might 499 be valuable to assess whether butyrate supplementation could reverse the deleterious neurocognitive and emotional effects of early malnutrition and/or mental pathologies.

The growing pigs used in our study were approximately 2 month-old at the beginning of the experiment. It is therefore likely that their brain functions and metabolism were still subject to plasticity mechanisms, and that their brain did not completely switch from monocarboxylates consumption during the early postnatal period to glucose consumption

505 later on. Chronic ingestion of sodium butyrate might modify the circulating levels of monocarboxylates, including butyrate and lactate. This could explain the decreased plasma lactate levels in SB pigs just before brain imaging, and the fact that plasma lactate levels were lower in SB than C pigs. In the hypothesis of an increased passage of butyrate and perhaps 509 lactate to the brain, the question of their interaction or competition with glucose can be raised.

510 The radioligand used in our study to investigate regional brain metabolism was a glucose 511 analogue $\left({ }^{18} \mathrm{~F}-\mathrm{FDG}\right)$ that is uptaken by brain cells, including glial cells and neurons. This exogenous glucose competes with endogenous glucose. Aside from the conventional view of

513 brain energy metabolism stating that glucose is consumed preferentially in neurons (22), an

514 alternative model suggests that glucose preferentially taken by astrocytes, is degraded to

515 lactate and then exported into neurons to be oxidized (60). Facing such a complex situation,

516 the only conclusion we can draw up upon our own results is that chronic consumption of 517 sodium butyrate during three weeks was sufficient to decrease basal plasma lactate levels and 518 modify the regional glucose metabolism in the hippocampus and nucleus accumbens. 

anatomy and function. Indeed, this treatment only tended to reduce gut secretory capacity and trans-cellular permeability in basal condition and lowered amino-peptidase $\mathrm{N}$ total activity in

522 the jejunum. By contrast, neither villus-crypt architecture nor para-cellular permeability and 523 inducible HSPs were affected. This is in contrast with our previous investigations in piglets 524 and calves $(12,13)$, possibly because in this experiment, the pigs were older and heavier than 525 previously. Based on the gut variables measured in the present experiment, this organ appears to contribute very little to the effects of butyrate observed at the brain level, but further explorations are needed to see whether butyrate might modulate other gastrointestinal tract parameters than those investigated in this study, and consequently send information to the brain to modulate its metabolism and plasticity. For example, peripheral and central immunity might be explored, as well as inflammation markers at both levels.

In conclusion, this study demonstrated that oral sodium butyrate influences regional brain metabolism and plasticity, and that the gut, systemic glucose control, or gut hormones variations appear to contribute very little to these effects. Further studies are needed to

534 determine whether the butyrate effects on brain metabolism and hippocampal plasticity can 535 improve neurocognition and mental welfare, especially when brain and behavioural disorders are observed. Different pig models are already available to investigate this question in the context of early malnutrition or diet-induced conditions. This would pave the way to a new treatment against nutritional- or stress-related psychological disorders.

\section{Acknowledgements}

This study was part of a research project (EPIMEMO) funded by Région Pays de la

542 Loire and coordinated by Jean-Pierre Segain and Patricia Parnet. The authors gratefully 
and Francis Legouevec for participating in this study and taking care of the animals.

\section{References}

1. Castanon, N., Luheshi, G., and Laye, S. (2015) Role of neuroinflammation in the emotional and cognitive alterations displayed by animal models of obesity. Frontiers in neuroscience 9, 229

2. Val-Laillet, D., Aarts, E., Weber, B., Ferrari, M., Quaresima, V., Stoeckel, L. E., Alonso-Alonso, M., Audette, M., Malbert, C. H., and Stice, E. (2015) Neuroimaging and neuromodulation approaches to study eating behavior and prevent and treat eating disorders and obesity. NeuroImage. Clinical 8, 1-31

3. Valvassori, S. S., Varela, R. B., Arent, C. O., Dal-Pont, G. C., Bobsin, T. S., Budni, J., Reus, G. Z., and Quevedo, J. (2014) Sodium butyrate functions as an antidepressant and improves cognition with enhanced neurotrophic expression in models of maternal deprivation and chronic mild stress. Current neurovascular research 11, 359-366

4. Sharma, S., Taliyan, R., and Singh, S. (2015) Beneficial effects of sodium butyrate in 6-OHDA induced neurotoxicity and behavioral abnormalities: Modulation of histone deacetylase activity. Behavioural brain research 291, 306-314

5. Guan, J. S., Haggarty, S. J., Giacometti, E., Dannenberg, J. H., Joseph, N., Gao, J., Nieland, T. J., Zhou, Y., Wang, X., Mazitschek, R., Bradner, J. E., DePinho, R. A., Jaenisch, R., and Tsai, L. H. (2009) HDAC2 negatively regulates memory formation and synaptic plasticity. Nature 459, 55-60

6. Gupta, S., Kim, S. Y., Artis, S., Molfese, D. L., Schumacher, A., Sweatt, J. D., Paylor, R. E., and Lubin, F. D. (2010) Histone methylation regulates memory formation. The Journal of neuroscience : the official journal of the Society for Neuroscience 30, 3589-3599

7. Levenson, J. M., O'Riordan, K. J., Brown, K. D., Trinh, M. A., Molfese, D. L., and Sweatt, J. D. (2004) Regulation of histone acetylation during memory formation in the hippocampus. The Journal of biological chemistry 279, 40545-40559

8. Stefanko, D. P., Barrett, R. M., Ly, A. R., Reolon, G. K., and Wood, M. A. (2009) Modulation of long-term memory for object recognition via HDAC inhibition.

Proceedings of the National Academy of Sciences of the United States of America 106, 9447-9452

9. Moretti, M., Valvassori, S. S., Varela, R. B., Ferreira, C. L., Rochi, N., Benedet, J., Scaini, G., Kapczinski, F., Streck, E. L., Zugno, A. I., and Quevedo, J. (2011) Behavioral and neurochemical effects of sodium butyrate in an animal model of mania. Behavioural pharmacology 22, 766-772

10. Bourassa, M. W., Alim, I., Bultman, S. J., and Ratan, R. R. (2016) Butyrate, neuroepigenetics and the gut microbiome: Can a high fiber diet improve brain health? Neuroscience letters 625, 56-63

11. Gorka, P., Kowalski, Z. M., Pietrzak, P., Kotunia, A., Kiljanczyk, R., Flaga, J., Holst, J. J., Guilloteau, P., and Zabielski, R. (2009) Effect of sodium butyrate supplementation in milk replacer and starter diet on rumen development in calves. 
602

603

604

605

606

607

608

609

610

611

612

613

614

615

616

617

618

619

620

621

622

623

624

625

626

627

628

629

630

631

632

633

634

635

Journal of physiology and pharmacology : an official journal of the Polish Physiological Society 60 Suppl 3, 47-53

12. Guilloteau, P., Zabielski, R., David, J. C., Blum, J. W., Morisset, J. A., Biernat, M., Wolinski, J., Laubitz, D., and Hamon, Y. (2009) Sodium-butyrate as a growth promoter in milk replacer formula for young calves. Journal of dairy science $\mathbf{9 2}$, 1038-1049

13. Le Gall, M., Gallois, M., Seve, B., Louveau, I., Holst, J. J., Oswald, I. P., Lalles, J. P., and Guilloteau, P. (2009) Comparative effect of orally administered sodium butyrate before or after weaning on growth and several indices of gastrointestinal biology of piglets. The British journal of nutrition 102, 1285-1296

14. Partanen, K. H., and Mroz, Z. (1999) Organic acids for performance enhancement in pig diets. Nutrition research reviews 12, 117-145

15. Guilloteau, P., Toullec, R., Patureau-Mirand, P., and Prugnaud, J. (1981) Importance of the abomasum in digestion in the preruminant calf. Reproduction, nutrition, developpement 21, 885-899

16. Zabielski, R., Dardillat, C., Le Huerou-Luron, I., Bernard, C., Chayvialle, J. A., and Guilloteau, P. (1998) Periodic fluctuations of gut regulatory peptides in phase with the duodenal migrating myoelectric complex in preruminant calves: effect of different sources of dietary protein. The British journal of nutrition 79, 287-296

17. Mazzoni, M., Le Gall, M., De Filippi, S., Minieri, L., Trevisi, P., Wolinski, J., LalattaCosterbosa, G., Lalles, J. P., Guilloteau, P., and Bosi, P. (2008) Supplemental sodium butyrate stimulates different gastric cells in weaned pigs. The Journal of nutrition 138, 1426-1431

18. Manzanilla, E. G., Nofrarias, M., Anguita, M., Castillo, M., Perez, J. F., Martin-Orue, S. M., Kamel, C., and Gasa, J. (2006) Effects of butyrate, avilamycin, and a plant extract combination on the intestinal equilibrium of early-weaned pigs. Journal of animal science 84, 2743-2751

19. Guilloteau, P., Zabielski, R., Hammon, H. M., and Metges, C. C. (2010) Nutritional programming of gastrointestinal tract development. Is the pig a good model for man? Nutrition research reviews $\mathbf{2 3}, 4-22$

20. Dienel, G. A., Liu, K., and Cruz, N. F. (2001) Local uptake of (14)C-labeled acetate and butyrate in rat brain in vivo during spreading cortical depression. $J$ Neurosci Res 66, $812-820$

21. Han, A., Sung, Y. B., Chung, S. Y., and Kwon, M. S. (2014) Possible additional antidepressant-like mechanism of sodium butyrate: targeting the hippocampus. Neuropharmacology 81, 292-302

22. Dienel, G. A. (2012) Brain lactate metabolism: the discoveries and the controversies. Journal of cerebral blood flow and metabolism : official journal of the International Society of Cerebral Blood Flow and Metabolism 32, 1107-1138

23. Gjedde, A., and Crone, C. (1975) Induction processes in blood-brain transfer of ketone bodies during starvation. The American journal of physiology 229, 1165-1169

24. Morris, A. A. (2005) Cerebral ketone body metabolism. Journal of inherited metabolic disease 28, 109-121

25. Redies, C., Hoffer, L. J., Beil, C., Marliss, E. B., Evans, A. C., Lariviere, F., Marrett, S., Meyer, E., Diksic, M., Gjedde, A., and et al. (1989) Generalized decrease in brain glucose metabolism during fasting in humans studied by PET. The American journal of physiology 256, E805-810

26. Courchesne-Loyer, A., Croteau, E., Castellano, C. A., St-Pierre, V., Hennebelle, M., and Cunnane, S. C. (2017) Inverse relationship between brain glucose and ketone metabolism in adults during short-term moderate dietary ketosis: A dual tracer 
661

662

663

664

665

666

667

668

669

670

671

672

673

674

675

676

677

678

679

680

681

682

683

684

quantitative positron emission tomography study. Journal of cerebral blood flow and metabolism : official journal of the International Society of Cerebral Blood Flow and Metabolism 37, 2485-2493

27. Zhang, Y., Kuang, Y., Xu, K., Harris, D., Lee, Z., LaManna, J., and Puchowicz, M. A. (2013) Ketosis proportionately spares glucose utilization in brain. Journal of cerebral blood flow and metabolism : official journal of the International Society of Cerebral Blood Flow and Metabolism 33, 1307-1311

28. Clouard, C., Meunier-Salaun, M. C., and Val-Laillet, D. (2012) Food preferences and aversions in human health and nutrition: how can pigs help the biomedical research? Animal : an international journal of animal bioscience 6, 118-136

29. Sauleau, P., Lapouble, E., Val-Laillet, D., and Malbert, C. H. (2009) The pig model in brain imaging and neurosurgery. Animal : an international journal of animal bioscience 3, 1138-1151

30. Roura, E., Koopmans, S. J., Lalles, J. P., Le Huerou-Luron, I., de Jager, N., Schuurman, T., and Val-Laillet, D. (2016) Critical review evaluating the pig as a model for human nutritional physiology. Nutrition research reviews 29, 60-90

31. Guilloteau, P., Martin, L., Eeckhaut, V., Ducatelle, R., Zabielski, R., and Van Immerseel, F. (2010) From the gut to the peripheral tissues: the multiple effects of butyrate. Nutrition research reviews $\mathbf{2 3}, 366-384$

32. Clouard, C., and Val-Laillet, D. (2014) Impact of sensory feed additives on feed intake, feed preferences, and growth of female piglets during the early postweaning period. Journal of animal science 92, 2133-2140

33. Gagliano, H., Delgado-Morales, R., Sanz-Garcia, A., and Armario, A. (2014) High doses of the histone deacetylase inhibitor sodium butyrate trigger a stress-like response. Neuropharmacology 79, 75-82

34. Khan, S., and Jena, G. (2016) Sodium butyrate reduces insulin-resistance, fat accumulation and dyslipidemia in type-2 diabetic rat: A comparative study with metformin. Chemico-biological interactions 254, 124-134

35. Boubaker, J., Val-Laillet, D., Guerin, S., and Malbert, C. H. (2012) Brain processing of duodenal and portal glucose sensing. Journal of neuroendocrinology 24, 1096-1105

36. Clouard, C., Jouhanneau, M., Meunier-Salaun, M. C., Malbert, C. H., and Val-Laillet, D. (2012) Exposures to conditioned flavours with different hedonic values induce contrasted behavioural and brain responses in pigs. PloS one 7, e37968

37. Clouard, C., Meunier-Salaun, M. C., Meurice, P., Malbert, C. H., and Val-Laillet, D. (2014) Combined compared to dissociated oral and intestinal sucrose stimuli induce different brain hedonic processes. Frontiers in psychology 5, 861

38. Val-Laillet, D., Besson, M., Guerin, S., Coquery, N., Randuineau, G., Kanzari, A., Quesnel, H., Bonhomme, N., Bolhuis, J. E., Kemp, B., Blat, S., Le Huerou-Luron, I., and Clouard, C. (2017) A maternal Western diet during gestation and lactation modifies offspring's microbiota activity, blood lipid levels, cognitive responses, and hippocampal neurogenesis in Yucatan pigs. FASEB journal : official publication of the Federation of American Societies for Experimental Biology

39. Zhang, J., and Jiao, J. (2015) Molecular Biomarkers for Embryonic and Adult Neural Stem Cell and Neurogenesis. BioMed research international 2015, 727542

40. Arvans, D. L., Vavricka, S. R., Ren, H., Musch, M. W., Kang, L., Rocha, F. G., Lucioni, A., Turner, J. R., Alverdy, J., and Chang, E. B. (2005) Luminal bacterial flora determines physiological expression of intestinal epithelial cytoprotective heat shock proteins 25 and 72. American journal of physiology. Gastrointestinal and liver physiology 288, G696-704 
41. Lalles, J. P., Boudry, G., Favier, C., and Seve, B. (2006) High-viscosity carboxymethylcellulose reduces carbachol-stimulated intestinal chloride secretion in weaned piglets fed a diet based on skimmed milk powder and maltodextrin. The British journal of nutrition 95, 488-495

42. Arnal, M. E., Zhang, J., Erridge, C., Smidt, H., and Lalles, J. P. (2015) Maternal antibiotic-induced early changes in microbial colonization selectively modulate colonic permeability and inducible heat shock proteins, and digesta concentrations of alkaline phosphatase and TLR-stimulants in swine offspring. PloS one 10, e0118092

43. Arnal, M. E., Zhang, J., Messori, S., Bosi, P., Smidt, H., and Lalles, J. P. (2014) Early changes in microbial colonization selectively modulate intestinal enzymes, but not inducible heat shock proteins in young adult Swine. PloS one 9, e87967

44. Chatelais, L., Jamin, A., Gras-Le Guen, C., Lalles, J. P., Le Huerou-Luron, I., and Boudry, G. (2011) The level of protein in milk formula modifies ileal sensitivity to LPS later in life in a piglet model. PloS one 6, e19594

45. Kisielinski, K., Willis, S., Prescher, A., Klosterhalfen, B., and Schumpelick, V. (2002) A simple new method to calculate small intestine absorptive surface in the rat. Clinical and experimental medicine 2, 131-135

46. Marion, J., Rome, V., Savary, G., Thomas, F., Le Dividich, J., and Le Huerou-Luron, I. (2003) Weaning and feed intake alter pancreatic enzyme activities and corresponding mRNA levels in 7-d-old piglets. The Journal of nutrition 133, 362-368

47. Saikali, S., Meurice, P., Sauleau, P., Eliat, P. A., Bellaud, P., Randuineau, G., Verin, M., and Malbert, C. H. (2010) A three-dimensional digital segmented and deformable brain atlas of the domestic pig. Journal of neuroscience methods 192, 102-109

48. Yadav, H., Lee, J. H., Lloyd, J., Walter, P., and Rane, S. G. (2013) Beneficial metabolic effects of a probiotic via butyrate-induced GLP-1 hormone secretion. The Journal of biological chemistry 288, 25088-25097

49. Canfora, E. E., van der Beek, C. M., Jocken, J. W. E., Goossens, G. H., Holst, J. J., Olde Damink, S. W. M., Lenaerts, K., Dejong, C. H. C., and Blaak, E. E. (2017) Colonic infusions of short-chain fatty acid mixtures promote energy metabolism in overweight/obese men: a randomized crossover trial. Scientific reports 7, 2360

50. During, M. J., Cao, L., Zuzga, D. S., Francis, J. S., Fitzsimons, H. L., Jiao, X., Bland, R. J., Klugmann, M., Banks, W. A., Drucker, D. J., and Haile, C. N. (2003) Glucagonlike peptide-1 receptor is involved in learning and neuroprotection. Nature medicine $\mathbf{9}$, 1173-1179

51. Zhang, Y., Zhang, S., Marin-Valencia, I., and Puchowicz, M. A. (2015) Decreased carbon shunting from glucose toward oxidative metabolism in diet-induced ketotic rat brain. Journal of neurochemistry 132, 301-312

52. Vanhoutvin, S. A., Troost, F. J., Hamer, H. M., Lindsey, P. J., Koek, G. H., Jonkers, D. M., Kodde, A., Venema, K., and Brummer, R. J. (2009) Butyrate-induced transcriptional changes in human colonic mucosa. PloS one 4, e6759

53. Donohoe, D. R., Wali, A., Brylawski, B. P., and Bultman, S. J. (2012) Microbial regulation of glucose metabolism and cell-cycle progression in mammalian colonocytes. PloS one 7, e46589

54. Fanselow, M. S., and Dong, H. W. (2010) Are the dorsal and ventral hippocampus functionally distinct structures? Neuron 65, 7-19

55. Pothuizen, H. H., Zhang, W. N., Jongen-Relo, A. L., Feldon, J., and Yee, B. K. (2004) Dissociation of function between the dorsal and the ventral hippocampus in spatial learning abilities of the rat: a within-subject, within-task comparison of reference and working spatial memory. The European journal of neuroscience 19, 705-712 
56. Mairesse, J., Gatta, E., Reynaert, M. L., Marrocco, J., Morley-Fletcher, S., Soichot, M., Deruyter, L., Camp, G. V., Bouwalerh, H., Fagioli, F., Pittaluga, A., Allorge, D., Nicoletti, F., and Maccari, S. (2015) Activation of presynaptic oxytocin receptors enhances glutamate release in the ventral hippocampus of prenatally restraint stressed rats. Psychoneuroendocrinology 62, 36-46

57. Bagot, R. C., Parise, E. M., Pena, C. J., Zhang, H. X., Maze, I., Chaudhury, D., Persaud, B., Cachope, R., Bolanos-Guzman, C. A., Cheer, J. F., Deisseroth, K., Han, M. H., and Nestler, E. J. (2015) Ventral hippocampal afferents to the nucleus accumbens regulate susceptibility to depression. Nature communications 6, 7062

58. Paillé, V., Boudin, H., Grit, I., Bonnet, C., de Coppet, P., Segain, J. P., and Parnet, P. (2014) Is perinatal butyrate intake, through maternal supplementation, able to prevent cognitive impairment due to intrauterine growth restriction in a rat model? In Journal of Developmental Origins of Health and Disease Vol. 6 p. S39, Proceedings of the second meeting the French-speaking society SF-DOHAD

59. Gieling, E. T., Nordquist, R. E., and van der Staay, F. J. (2011) Assessing learning and memory in pigs. Animal cognition 14, 151-173

60. Barros, L. F., and Deitmer, J. W. (2010) Glucose and lactate supply to the synapse. Brain research reviews 63, 149-159 
Table 1. Brain structures presenting a higher $(\mathrm{SB}>\mathrm{C})$ or lower $(\mathrm{SB}<\mathrm{C})$ glucose metabolism (expressed in Standard Uptake Value) in butyratesupplemented piglets (SB group) compared to control piglets (C group) using a "without a priori" first-level global analysis and a "with a priori" second-level small volume correction (SVC) analysis. The SVC analysis included the following regions of interest (ROI): anterior prefrontal cortex, dorsolateral prefrontal cortex, orbitofrontal cortex, cingulate cortex, hippocampus, parahippocampal cortex, amygdala, caudate, putamen, nucleus accumbens, globus pallidus. The peak $t$-value, uncorrected $P$-value and coordinates in the CA-CP (commissura anterior-commissura posterior) reference plane are indicated for each significant cluster comprising at least 25 voxels, for the left (L) and/or right (R) hemispheres.

\begin{tabular}{|c|c|c|c|c|c|c|c|}
\hline \multirow[b]{2}{*}{ Brain structures } & \multirow[b]{2}{*}{ Side } & \multicolumn{3}{|c|}{$\mathrm{SB}>\mathrm{C}$} & \multicolumn{3}{|c|}{ SB $<\mathbf{C}$} \\
\hline & & $\begin{array}{c}\text { Peak } \\
t\end{array}$ & $\begin{array}{l}\text { Peak } \\
P(\text { unc) }\end{array}$ & $\mathrm{x}, \mathrm{y}, \mathrm{z}$ & $\begin{array}{c}\text { Peak } \\
\mathrm{t}\end{array}$ & $\begin{array}{l}\text { Peak } \\
P(\text { unc })\end{array}$ & $\mathrm{x}, \mathrm{y}, \mathrm{z}$ \\
\hline \multicolumn{8}{|l|}{$\begin{array}{l}\text { First-level global } \\
\text { analysis }\end{array}$} \\
\hline \multirow[t]{2}{*}{$\begin{array}{l}\text { Primary } \\
\text { somatosensory cortex }\end{array}$} & $\mathrm{L}$ & & & & 3.48 & 0.002 & -141918 \\
\hline & $\mathrm{R}$ & 4.39 & $<0.001$ & 81525 & & & \\
\hline $\begin{array}{l}\text { Inferior temporal } \\
\text { gyrus }\end{array}$ & $\mathrm{L}$ & & & & 3.13 & 0.004 & -2656 \\
\hline Inferior colliculus & $\mathrm{L}$ & 3.38 & 0.002 & $-8-8-2$ & & & \\
\hline Hippocampus & $\mathrm{R}$ & 3.35 & 0.003 & $123-3$ & & & \\
\hline \multicolumn{8}{|l|}{$\begin{array}{l}\text { Second-level SVC } \\
\text { analysis }\end{array}$} \\
\hline Hippocampus & $\mathrm{R}$ & 3.32 & 0.003 & $123-4$ & 2.67 & 0.010 & $10-29$ \\
\hline Nucleus accumbens & $\mathrm{R}$ & & & & 2.66 & 0.010 & $219-4$ \\
\hline
\end{tabular}


530 Table 2. Gut electrophysiology parameters determined ex vivo in Ussing chambers ( $\mathrm{n}=6-8$ per treatment).

\begin{tabular}{|c|c|c|c|c|c|c|c|c|c|c|c|}
\hline & \multirow{2}{*}{$\begin{array}{r}\text { Site } \\
\text { Treatments }^{2} \\
\end{array}$} & \multicolumn{2}{|c|}{ Jejunum } & \multicolumn{2}{|c|}{ Ileum } & \multicolumn{2}{|c|}{ Colon } & \multirow[b]{2}{*}{ SEM } & \multicolumn{3}{|c|}{ Statistics $(P=)^{1}$} \\
\hline & & $\mathbf{C}$ & SB & $\mathbf{C}$ & SB & $\mathbf{C}$ & SB & & Tr. & Site & Tr.*Site \\
\hline \multicolumn{12}{|l|}{ Basal condition $^{3}$} \\
\hline $\mathrm{Isc}\left(\mu \mathrm{A} / \mathrm{cm}^{2}\right)$ & & 47 & 70 & 37 & 25 & 62 & 57 & 32 & 0.96 & 0.13 & 0.38 \\
\hline $\operatorname{TEER}\left(\Omega \times \mathrm{cm}^{2}\right)$ & & 50 & 49 & 57 & 51 & 46 & 28 & 10 & 0.25 & 0.44 & 0.79 \\
\hline dIsc-glucose $\left(\mu \mathrm{A} / \mathrm{cm}^{2}\right)$ & & 8 & 11 & 17 & 9 & 6 & 3 & 8 & 0.78 & 0.66 & 0.41 \\
\hline dIsc-carbachol $\left(\mu \mathrm{A} / \mathrm{cm}^{2}\right)$ & & 21 & 14 & 32 & 5 & 51 & 20 & 12 & 0.09 & 0.27 & 0.21 \\
\hline \multicolumn{12}{|c|}{ Under oxidant stress (monochloramine, $\mathrm{MC})^{2}$} \\
\hline $\mathrm{dIsc}-\mathrm{MC}\left(\mu \mathrm{A} / \mathrm{cm}^{2}\right)$ & & 5 & -55 & 6 & 5 & -44 & -115 & 36 & 0.29 & 0.19 & 0.63 \\
\hline dIsc-glucose $\left(\mu \mathrm{A} / \mathrm{cm}^{2}\right)$ & & 4.7 & 1.0 & 4.8 & 1.2 & 1.8 & 2.6 & 2.5 & 0.49 & 0.68 & 0.04 \\
\hline dIsc-carbachol $\left(\mu \mathrm{A} / \mathrm{cm}^{2}\right)$ & & 21 & 11 & 18 & 12 & 32 & 5 & 8 & 0.18 & 0.96 & 0.64 \\
\hline
\end{tabular}

${ }^{1}$ Tr.: Treament; $\operatorname{Tr} .{ }^{*}$ Site: treatment by site interaction.

$532 \quad{ }^{2}$ Treatments: C: control; SB: sodium butyrate.

$533{ }^{3}$ Isc: short-circuit current; TEER: trans-epithelial electrical resistance; dIsc: variation in Isc (following glucose or carbachol or monochloramine addition). 
Table 3. Influence of site and dietary treatment on gut para- and trans-cellular permeabilities determined ex vivo in Ussing chambers (log-

transformed data; $n=6-8$ per treatment).

\begin{tabular}{|c|c|c|c|c|c|c|c|c|c|c|c|}
\hline \multirow{2}{*}{\multicolumn{2}{|c|}{$\begin{array}{r}\text { Site } \\
\text { Treatments }^{2}\end{array}$}} & \multicolumn{2}{|c|}{ Jejunum } & \multicolumn{2}{|c|}{ Ileum } & \multicolumn{2}{|c|}{ Colon } & \multirow[b]{2}{*}{ SEM } & \multicolumn{3}{|c|}{ Statistics $(\mathbf{P}=)^{1}$} \\
\hline & & $\mathrm{C}$ & SB & $\mathbf{C}$ & SB & $\mathbf{C}$ & SB & & Tr. & Site & Tr.*Site \\
\hline FD4 (ng/cm²/h, log) & & 2.9 & 2.9 & 3.1 & 2.8 & 3.0 & 2.9 & 0.10 & 0.15 & 0.73 & 0.15 \\
\hline \multicolumn{12}{|c|}{ Under oxidant stress (monochloramine) } \\
\hline FD4 $\left(\mathrm{ng} / \mathrm{cm}^{2} / \mathrm{h}, \log \right)$ & & 2.8 & 2.9 & 3.1 & 2.9 & 3.1 & 2.9 & 0.09 & 0.49 & 0.34 & 0.49 \\
\hline
\end{tabular}

536 Tr.: Treament; Tr.*Site: treatment by site interaction.

$537 \quad{ }^{2}$ Treatments: C: control; SB: sodium butyrate.

$538{ }^{3}$ FD4: Fluorescein dextran 4000 (para-cellular permeability marker, $4 \mathrm{kDa}$ ); HRP: horseradish peroxidase (trans-cellular permeability marker, $40 \mathrm{kDa}$ ). 
Table 4. Influence of dietary treatment on body weight, relative pancreas weight and protein concentration, and specific and total activities of the pancreatic enzymes ( $\mathrm{n}=7-8$ per treatment).

\begin{tabular}{|c|c|c|c|c|}
\hline Treatment & $\mathbf{C}$ & SB & SEM & $\begin{array}{c}\text { Statistics } \\
(\mathrm{P}=)\end{array}$ \\
\hline Body weight (Kg) & 42.3 & 41.8 & 1.2 & 0.95 \\
\hline Fresh pancreas weight $\left(\mathrm{mg} / \mathrm{kg} \mathrm{BW}^{1}\right)$ & 2.25 & 2.13 & 0.8 & 0.39 \\
\hline \multicolumn{5}{|l|}{ Pancreas protein } \\
\hline $\mathrm{mg} / \mathrm{g}$ fresh pancreas & 207.7 & 201.5 & 12.6 & 0.77 \\
\hline $\mathrm{mg} / \mathrm{kg} \mathrm{BW}$ & 468.2 & 431.8 & 37.4 & 0.88 \\
\hline \multicolumn{5}{|l|}{ Specific activities $^{2}$ (/g fresh pancreas) } \\
\hline Trypsin (IU) & 444.3 & 404.2 & 35.6 & 0.89 \\
\hline Amylase $\left(10^{-3} \mathrm{IU}\right)$ & 7.2 & 7.5 & 0.8 & 0.37 \\
\hline Lipase $\left(10^{-3} \mathrm{IU} /\right)$ & 79.8 & 81.1 & 9.5 & 0.45 \\
\hline \multicolumn{5}{|l|}{ Relative activities $\left.^{2}(/ \mathbf{k g ~ B W})^{1}\right)$} \\
\hline Trypsin $\left(10^{3} \mathrm{IU}\right)$ & 208.7 & 175.3 & 21.8 & 0.44 \\
\hline Amylase (IU) & 32.8 & 33.1 & 4.4 & 0.52 \\
\hline Lipase (IU) & 38.0 & 34.2 & 5.8 & 0.69 \\
\hline
\end{tabular}

544

${ }^{2} \mathrm{IU}=\mathrm{mmol}$ substrate hydrolyzed $/ \mathrm{min}$. 
547 Table 5. Influence of site and dietary treatment on enzyme activities along the gut ( $\mathrm{n}=7-8$ per treatment).

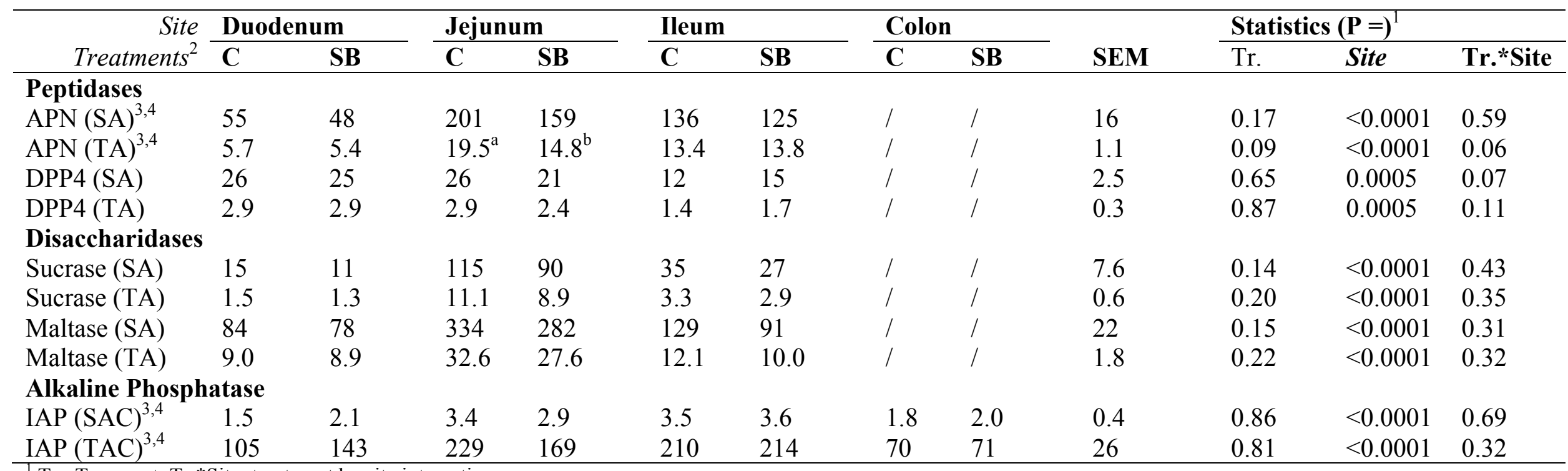

${ }^{1}$ Tr.: Treament; Tr.*Site: treatment by site interaction.

$549{ }^{2}$ Treatments: C: control; SB: sodium butyrate.

$550 \quad{ }^{3}$ APN: amino-peptidase N; DPP4: dipeptidyl-peptidase 4; IAP: intestinal alkaline phosphatase.

$551{ }^{4}$ SA: Specific activity ( $\mu$ moles $/ \mathrm{min} / \mathrm{mg}$ protein; nmoles $/ \mathrm{min} / \mathrm{mg}$ protein for DPP4); SAC: Specific activity concentration for IAP ( $\mu$ g IAP/g protein). TA: total activity

$552(\mu \mathrm{moles} / \mathrm{min} / \mathrm{g}$ fresh mucosa; nmoles $/ \mathrm{min} / \mathrm{g}$ fresh mucosa for DPP4); TAC: Total activity concentration for IAP ( $\mu \mathrm{g}$ IAP/g fresh tissue).

$553 \quad{ }_{\mathrm{a}, \mathrm{b}} \mathrm{P}<0.05$ 
786 Fig 1. Changes in plasma concentrations of (A) lactate, (B) PYY and (C) GLP-1 before and

787 after drinking the beverages (both groups merged: pigs received either pure water (control) or

788 sodium butyrate-supplemented beverage). (D) Differences in plasma osmolality between

789 groups and sampling time. (E) Plasma lactate concentration a week later, just before brain

790 imaging.

791

792 Fig 2. Sagittal and axial magnetic resonance imaging models and sections showing the main

793 brain structures of differential glucose metabolism identified during the statistical parametric

794 mapping (SPM) analysis for the contrast butyrate $v s$. control. A) Three-dimensional brain

795 models showing the whole structures of interest. B) Magnetic resonance imaging sections

796 showing the significant clusters of brain activation or deactivation. The $\mathrm{x}$ or $\mathrm{y}$ coordinates in

797 the commissura anterior-commissura posterior (CA-CP) plane are indicated below the

798 images. The statistical threshold was set at $P<0.01$ (uncorrected). Red spots indicate a

799 glucose metabolism higher in SB group compared to C group. Blue spots indicate a glucose

800 metabolism lower in SB group compared to C group. HIP: hippocampus; NAc: nucleus

801 accumbens; ISSC: primary somatosensory cortex.

802

803 Fig 3. Hippocampal and granular cell layer (GCL) volume determination along the

804 hippocampus sections. A) Representative view of 10 sections covering the first $7.5 \mathrm{~mm}$ of

805 hippocampus. B) Calculated block volume for each site. The presented values are considering

806 the entire block of 25 sections of $30 \mu \mathrm{m}$ each, and give an insight of the overall volume of the

807 hippocampus and the GCL. Significant difference between treatments was found for GCL

808 volume only. Data are presented as mean \pm SEM.

809 
810 Fig 4. Hippocampal structural plasticity. A) Immunostaining of brain sections showing Ki67811 positive nucleus distribution (left) and DCX-positive (doublecortin, right) cells within the 812 granular cell layer (GCL) of the hippocampus. B) Quantification of Ki67-positive nucleus in 813 the sub granular zone (SGZ, left) and DCX-positive cells in the GCL along the hippocampus. 814 The presented values are considering the entire block of 25 sections of $30 \mu \mathrm{m}$ for each 815 histological slice. Significant differences were found between dietary treatments for Ki67 and 816 DCX. Data are presented as mean \pm SEM. An asterisk indicates a significant difference at $817 \quad P<0.05$. 
A)

Back

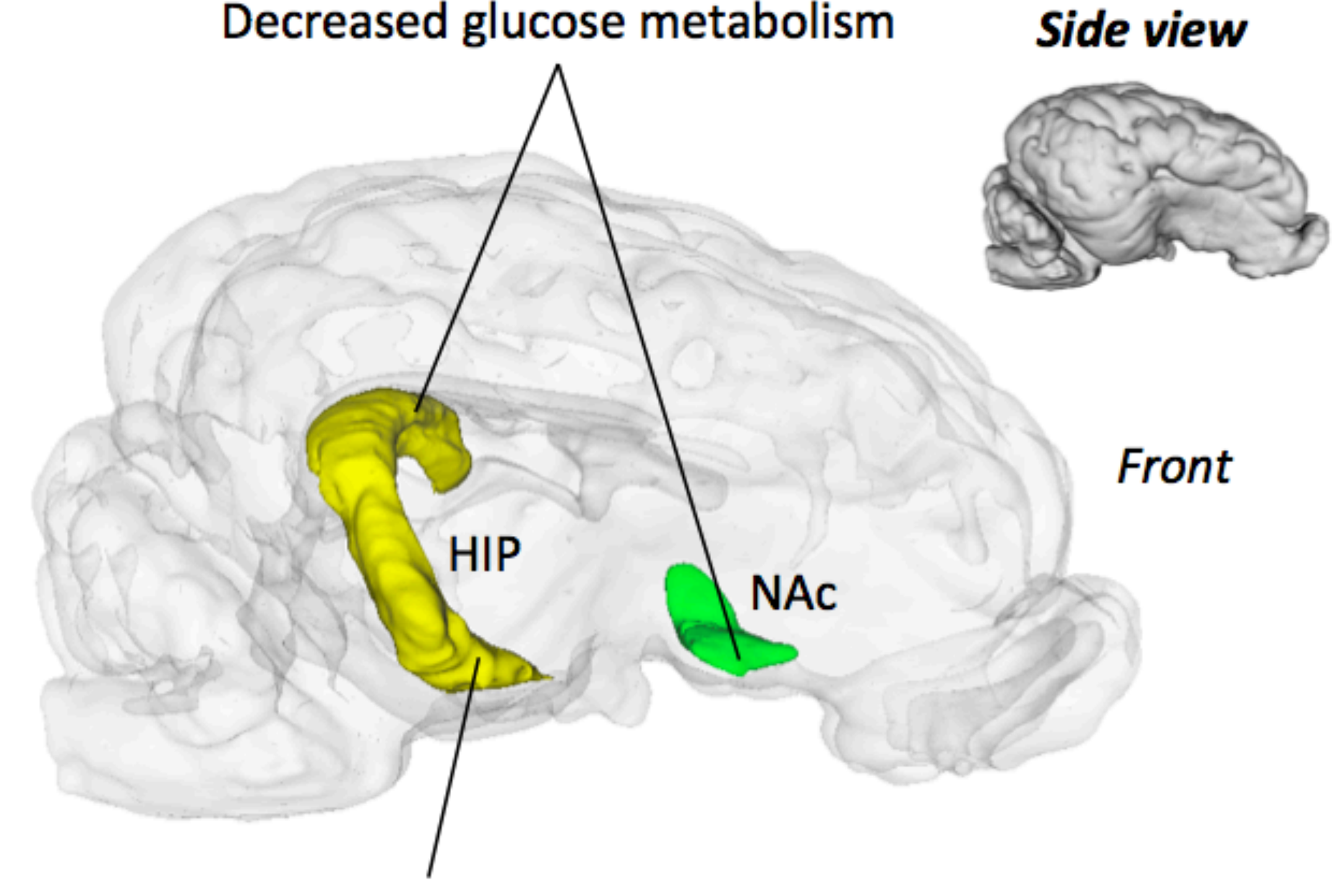

Increased glucose metabolism

Right

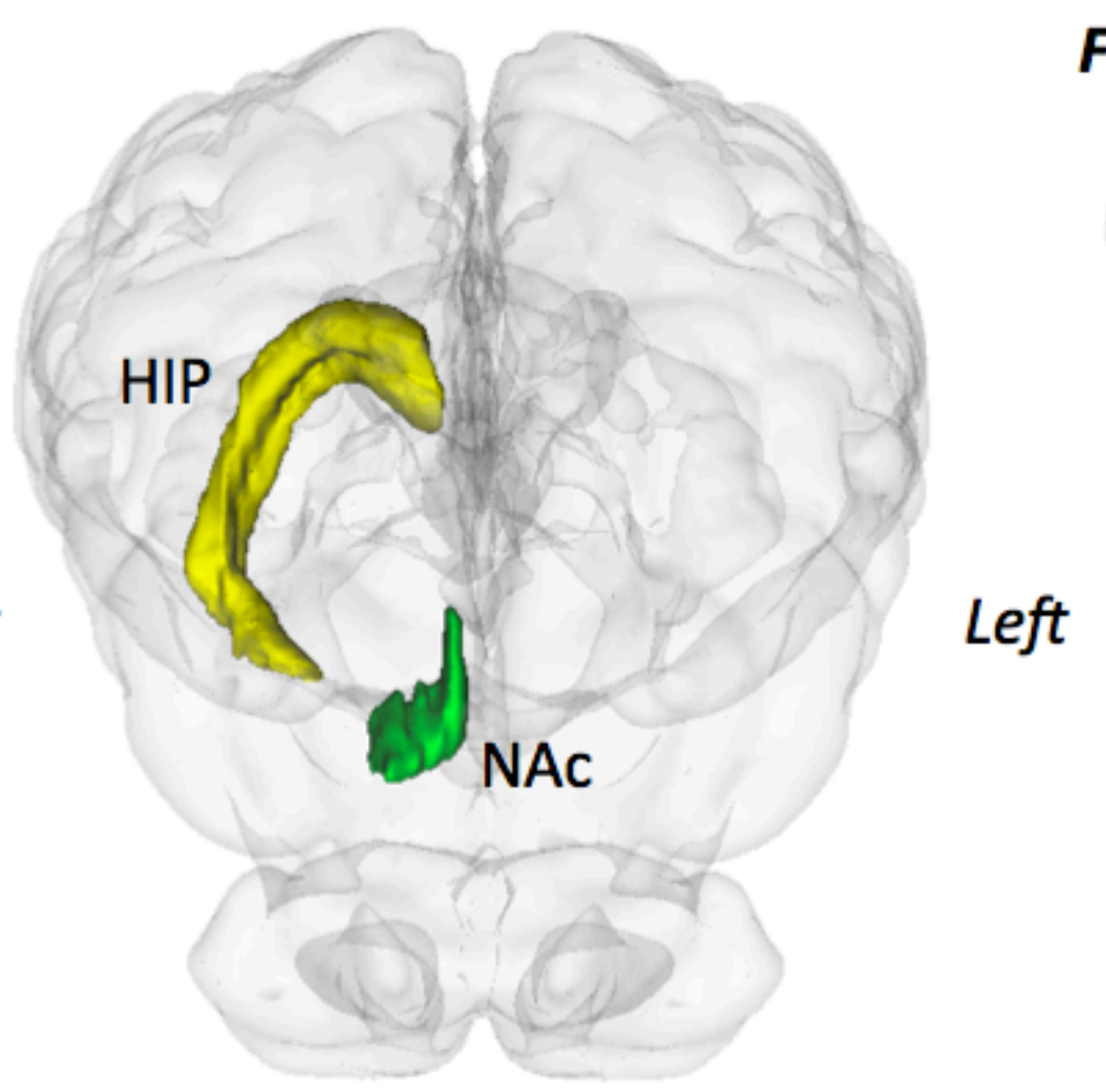

Front view

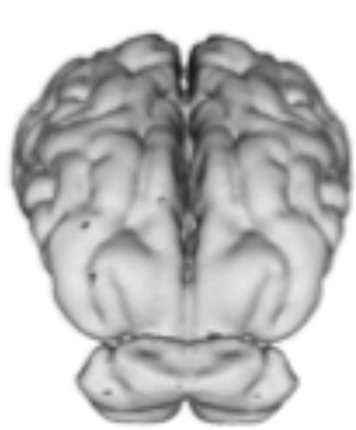

B)

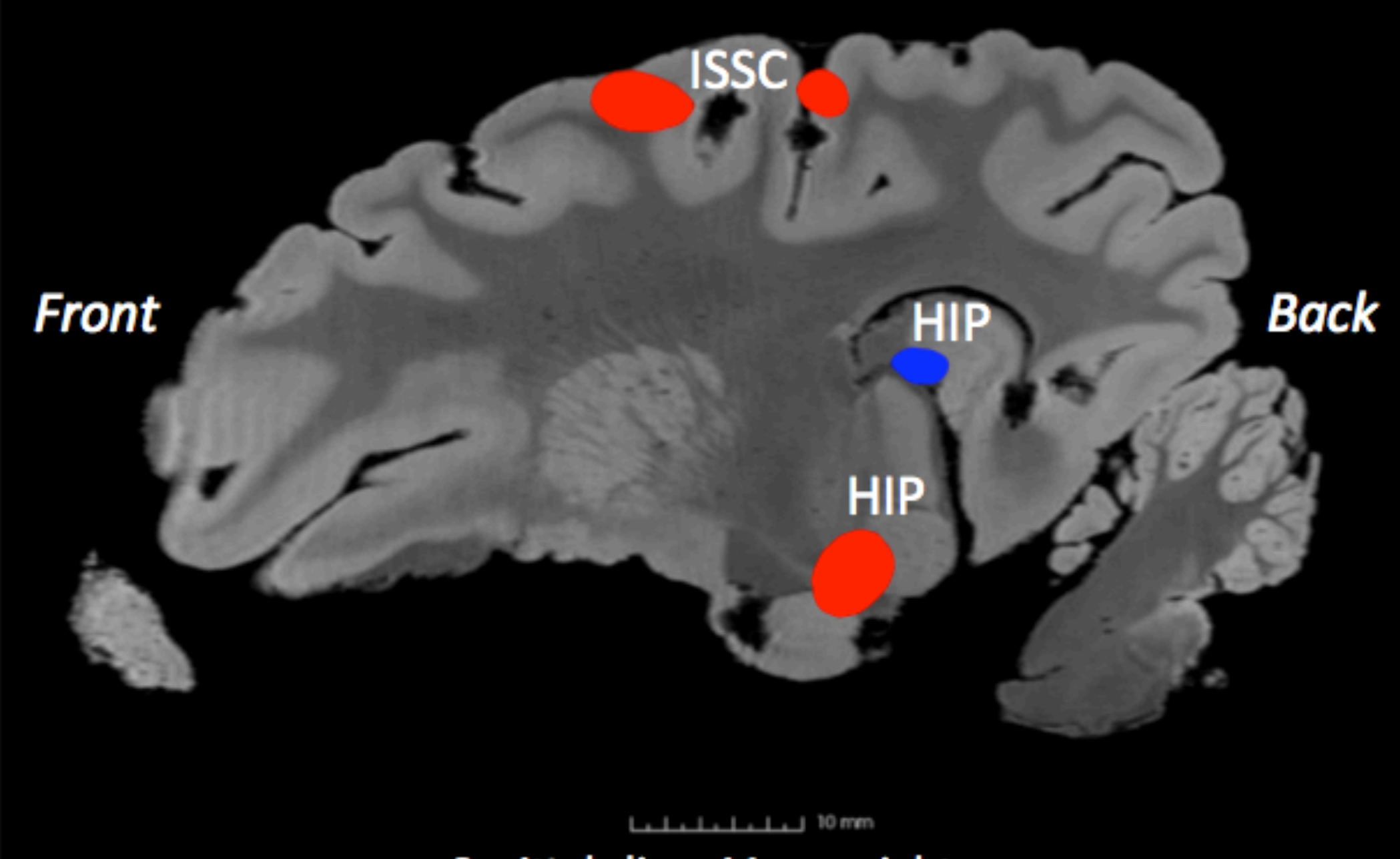

Sagittal slice: $11 \mathrm{~mm}$ right

Right

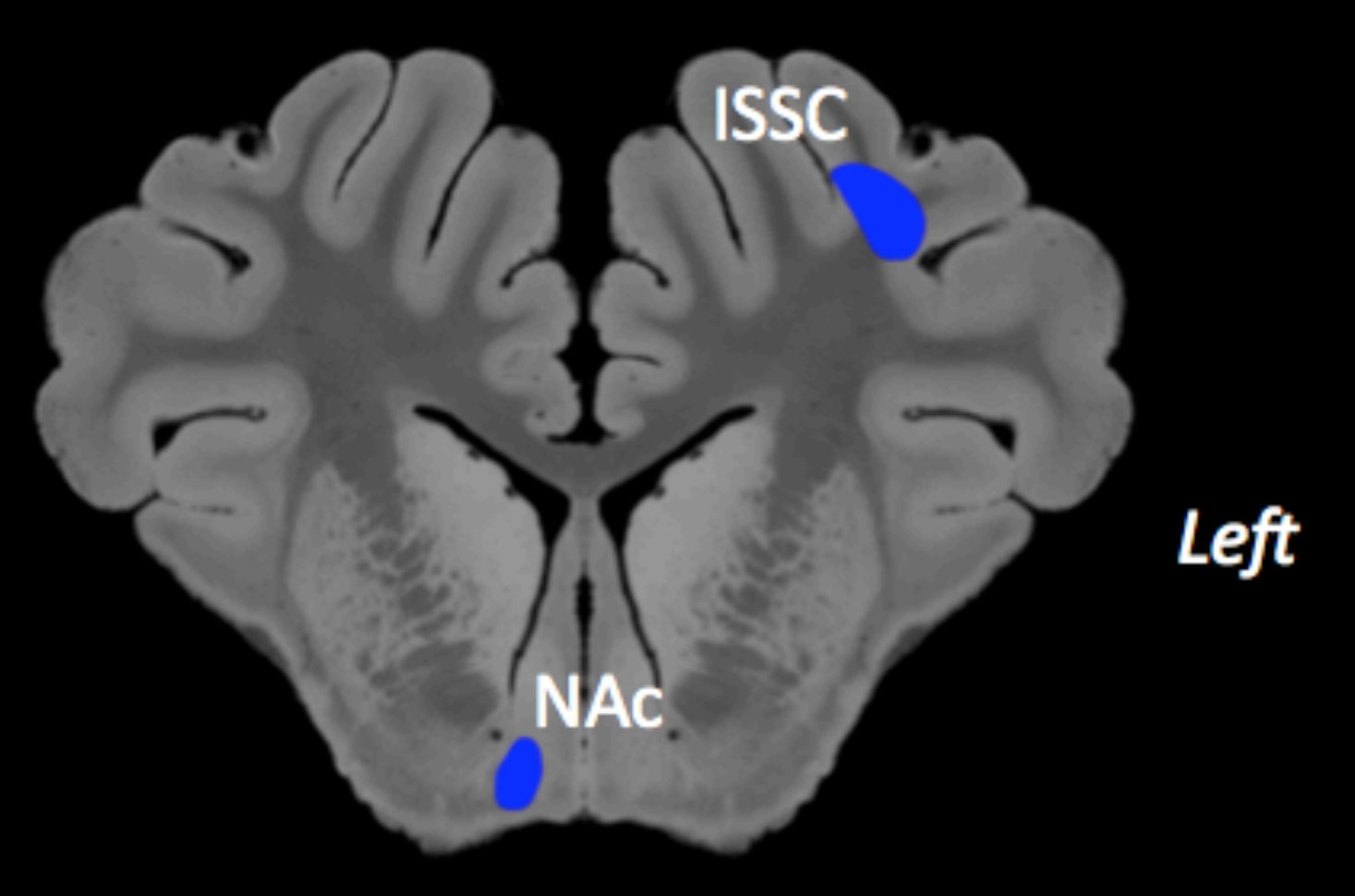

Axial slice: $19 \mathrm{~mm}$ front 


\section{$\mathbf{A}$ \\ Hippocampal site progression (DAPI)}
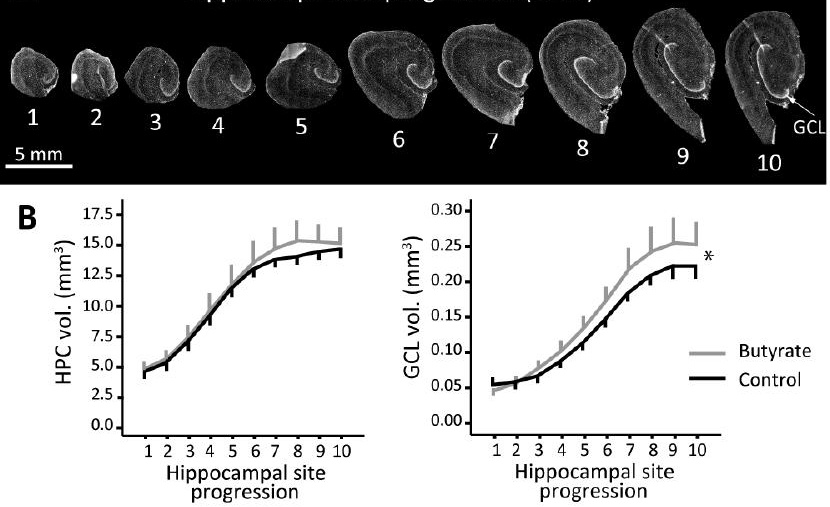
O

Control

$100 \mu \mathrm{m}$

Control

$100 \mu \mathrm{m}$

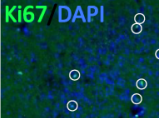

Butyrate

$100 \mu \mathrm{m}$ Butyrate

$100 \mu \mathrm{m}$
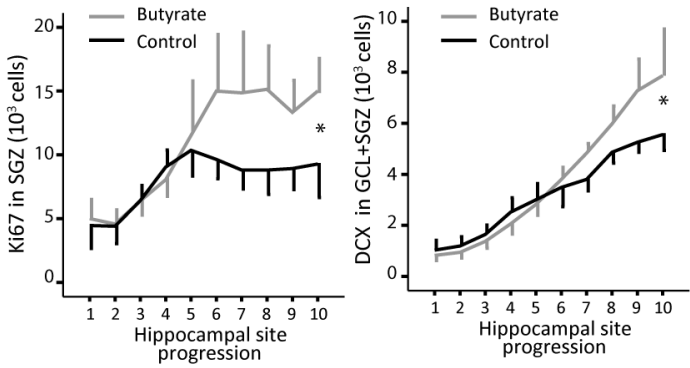